\title{
A Study on the Synergistic Change of Non-ferrous Metal Futures and Stock Prices in China-Based on the Complex System Synergy Degree
}

\author{
Qingxin Kong1,a, Shangde Gou ${ }^{1}$ \\ ${ }^{1}$ Tianjin University of Finance and Economics, China
}

\begin{abstract}
Based on the synergetics perspective, this paper constructs a composite system of non-ferrous metal futures and stock prices, using MATLAB to analyze the data of 3405 trading days from 2004 to 2018 in China. The empirical results show that non-ferrous metal stock prices are generally more orderly than futures prices in the selected period; the price discovery function of aluminum futures is worse than that of copper and zinc; and the 2008 financial crisis has an indelible negative impact on the coordination of China's non-ferrous metals futures market. Finally, this paper discusses whether there are representative metals in the non-ferrous metal market, and makes a brief summary.
\end{abstract}

\section{Introduction and literature review}

Before 2000, the overall performance of the commodity market was not active. Its correlation with the stock market is not high, and the correlation between different varieties in the commodity market is also low. After 2004, the correlation between commodity futures prices of different varieties increased significantly. After 2008, the correlation between commodity futures prices and stock index also increased significantly. The academia called this phenomenon the financialisation of commodities

In recent years, many scholars have studied the relationship between futures market and stock market. Theoretically, Kyle and Xiong (2001) constructs the wealth effect model to explain the infection mechanism. Yang Ruijie and Zhang Xiangli (2016) study from the perspective of price advance, volatility advance and no arbitrage. Wang Daoping and Jia Yuning (2018) used Commodity Confidence Index (CCI), Directed Acyclic Graph (DAG) and VAR model to study the relationship between Chinese commodity prices and investor sentiment, inflation. From the perspective of system theory, Ren Teng and Zhou Zhongbao (2017) combined the cooperative theory with the particle swarm optimization (DNLPSO) based on dynamic neighborhood and local search, and constructed the dynamic cooperative evolution model of the insurance, credit and stock financial system.

There are many previous studies on the linkage relationship between futures price and stock price, but few scholars regard each financial market as a complex system to study the synergetic development between them. However, the existing research on the linkage relationship between futures price and equity price is limited to the single stock data representative of a certain industry.

This paper collected data of a total of 3,405 trading days from October 8, 2004 to October 9, 2018 and established the composite system. In this paper, order parameter order degree, entropy weight and synergy degree are calculated by MATLAB.

\section{Theoretical basis}

In 1971, physicist Hermann put forward the concept of "synergy". Synergetics regards all research objects as a system composed of subsystems or elements, each of which is in an interrelated and influential situation. The interaction among subsystems may be synergy or vice versa. The overall level moves from disorder to order and relies on the synergy of order parameters.

\subsection{Order degree of order parameter}

In Order parameter is an important reference index to reflect the degree of system order, which refers to the change of "from nothing to something" in the process of system evolution. Composite system $\mathrm{S}=\mathrm{f}(\mathrm{S} 1, \mathrm{~S} 2, \ldots \mathrm{In} \mathrm{Sm}$, there are subsystems $\mathrm{Sj}, \mathrm{j} \in[1, \mathrm{~m}]$. Based on the evolution of subsystem $\mathrm{Sj}$, it contains $\mathrm{N}$ sequence parameters, $\mathrm{ej}=\{\mathrm{ej} 1, \mathrm{ej} 2, \ldots \mathrm{EjN}\}$, where $\mathrm{N}$ is greater than 1 , alpha $\mathrm{ji}<\mathrm{eji}<$ beta $\mathrm{Ji}, \mathrm{i} \in[1, \mathrm{~N}]$. The order degree of the first order parameter Eji in the system $\mathrm{Sj}$ at time $\mathrm{t}$, where alpha and beta are the lower and upper bounds of the order parameter Eji at the critical point of system stability. Generally, assuming the first one to $\mathrm{K}$ order parameters, ej 1 and ej 2 are positive order parameters, that is, the 
larger the value, the higher the degree of order of the system.

$$
\mu_{j i}(t)\left\{\begin{array}{c}
\frac{e_{j i}(t)-\alpha_{j i}}{\beta_{j i}-\alpha_{j i}}, i \in\left[1, K_{1}\right] \\
\frac{\beta_{j i}-e_{j i}(t)}{\beta_{j i}-\alpha_{j i}}, i \in\left[K_{1}+1, n\right]
\end{array}\right.
$$

\subsection{Coordination degree of composite system}

At time $t$, the contribution of each order parameter to the ordering degree of subsystem $\mathrm{Sj}$ can be realized by integrating the ordering degree of multiple order parameters in the subsystem. The ordering degree of subsystem $\mathrm{Sj}$ depends not only on the ordering degree of each order parameter, but also on the data structure of the subsystem. The linear weighting method is usually used to calculate the order degree of the subsystem $\mathrm{Sj}$.Order degree of order parameter is shown in Table 1.

$$
\begin{gathered}
\mu_{j}(t)=\sum_{\mathrm{i}=1}^{N} w_{j i}^{1} \mu_{j i}(t), \\
w_{j i}^{1} \geq 0, i=1,2, \cdots, N, \sum_{\mathrm{i}=1}^{N} w_{j i}^{1}=1
\end{gathered}
$$

Table 1. Order parameter of subsystem $\mathrm{Sj}$.

\begin{tabular}{|c|c|c|c|c|}
\hline & ej1 & ej2 & $\ldots$ & ejn \\
\hline $\mathrm{t} 1$ & $\mathrm{Uj} 1(\mathrm{t} 1)$ & $\mathrm{Uj} 2(\mathrm{t} 1)$ & $\ldots$ & $\mathrm{Ujn}(\mathrm{t} 1)$ \\
\hline $\mathrm{t} 2$ & $\mathrm{Uj} 1(\mathrm{t} 2)$ & $\mathrm{Uj} 2(\mathrm{t} 2)$ & $\ldots$ & $\mathrm{Ujn}(\mathrm{t} 2)$ \\
\hline$\ldots$ & $\ldots$ & $\ldots$ & $\ldots$ & $\ldots$ \\
\hline $\mathrm{tT}$ & $\mathrm{Uj} 1(\mathrm{tT})$ & $\mathrm{Uj} 2(\mathrm{tT})$ & $\ldots$ & $\mathrm{Ujn}(\mathrm{t} T)$ \\
\hline
\end{tabular}

The probability distribution of the ordinal parameter Eji can be seen as:

$$
P_{\mathrm{ji}}^{1}(t)=\frac{\mu_{j i}(t)}{\sum_{\mathrm{t}=t_{1}}^{t_{T}} \mu_{j i}(t)}, t=t_{1}, t_{2}, \cdots t_{T} . i=1,2, \cdots, N
$$

The entropy of order parameter Eji is:

$$
H^{1}{ }_{j i}=-\frac{1}{\ln T} \sum_{\mathrm{t}=\hbar_{1}}^{t_{T}} P^{1}{ }_{\mathrm{ji}}(t) \ln P_{\mathrm{ji}}^{1}(t), i=1,2, \cdots, N
$$

The entropy weight of order parameter Eji is:

$$
w_{j i}^{1}=\frac{1-H_{j i}^{1}}{\sum_{i=1}^{N}\left(1-H_{j i}^{1}\right)}, i=1,2, \cdots, N
$$

The entropy and entropy weights of subsystems are also calculated by this method.

\subsection{Coordination degree of composite system}

It is assumed that the price system of non-ferrous metals is a complex system composed of several subsystems, which can be denoted as $\mathrm{S}=(\mathrm{S} 1, \mathrm{~S} 2, \ldots, \mathrm{Sn})$, and $\mathrm{S} \mathrm{J}$ is the J subsystem.

$$
\begin{gathered}
S D_{e}\left(t, t_{0}\right)=\eta_{e} \sum_{\mathrm{i}=1}^{N} w^{1}{ }_{j i}\left|\mu_{j i}(t)-\mu_{j i}\left(t_{0}\right)\right| \\
\eta_{e}=\left\{\begin{array}{c}
1, \lim _{i=1,2, \cdots, N}\left\{\mu_{j i}(t)-\mu_{j i}\left(t_{0}\right)\right\} \geq 0 \\
-1, \lim _{i=1,2, \cdots, N}\left\{\mu_{j i}(t)-\mu_{j i}\left(t_{0}\right)\right\}<0
\end{array}, \mathrm{e}=\left\{e_{j 1}, e_{j 2}, \cdots, e_{j N}\right\}\right.
\end{gathered}
$$

\subsection{Model establishment}

The composite system s1-s6 for establishing the nonferrous metal market is shown in table 2. Copper, aluminum and zinc are the representatives of non-ferrous metals. In this paper, the stock prices of three companies with business relevance above $50 \%$ and the corresponding futures contract prices are selected as the measurement indexes for each metal.

Table 2. The complex system of the non-ferrous metal market.

\begin{tabular}{|c|c|}
\hline Subsystem Name & Variables Name \\
\hline S1 & Future price of copper \\
\hline S2 & Copper stock price \\
\hline S3 & Future price of aluminum \\
\hline S4 & Aluminum stock price \\
\hline S5 & Future price of zinc \\
\hline S6 & Zinc stock price \\
\hline
\end{tabular}

\subsection{Put forward the hypothesis}

Hypothesis 1: In a composite system, the order degree of different subsystems is different, and the evolution process is different.

Hypothesis 2: Before and after the financial crisis of 2007-2008, the degree of cooperation among the subsystems would change significantly.

Hypothesis 3: There is an industry representative metal, which has a high degree of synergy with other metals.

\section{Empirical test and analysis}

In this part, we have made an overall analysis of the price system of non-ferrous metals.

\subsection{Compare the order degree of the futures and stock subsystems of the three non-ferrous metals}

In this part, we calculated the order degree of each subsystem's order parameters and the corresponding 
entropy weight, and calculated the order degree of each subsystem according to them, and obtained figure 1 and figure 2 .

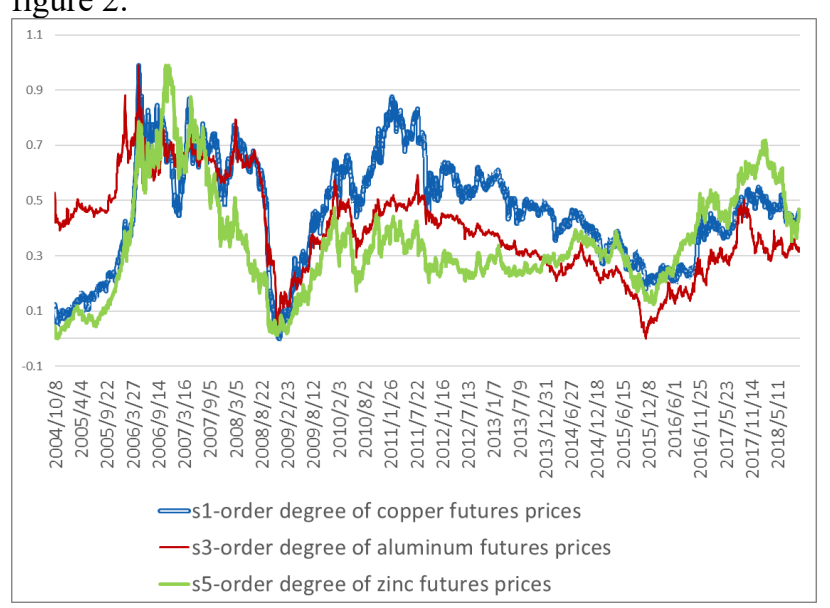

Figure 1. Non-ferrous metal (copper, aluminum, zinc) futures system order degree.

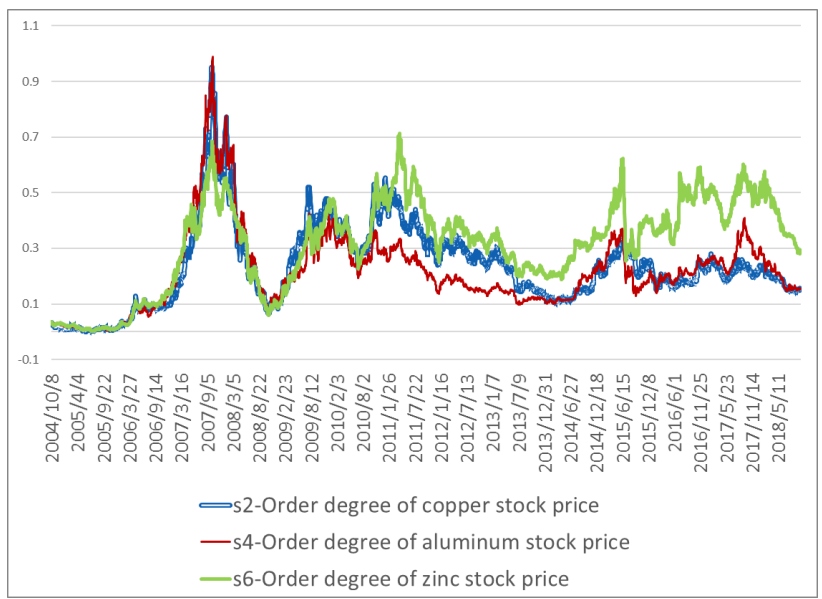

Figure 2. Non-ferrous metal (copper, aluminum, zinc) stock system order degree.

Since 2004, the Chinese economy has seen rapid growth after many years of ups and downs. In 2004, the correlation coefficient of production, consumption and GDP of major metals like copper, aluminum and zinc all exceeded 0.9. Along with the financialization of commodities, non-ferrous metal futures and stock markets have steadily increased in order.

From 2007 to 2009, the order degree of the nonferrous metal futures market all reached the peak, and then as a result of the financial crisis, a nearly straight line of decline.

From 2010 to 2011, environmental problems became a "green barrier" for the development of non-ferrous metals industry, due to frequent thallium pollution at the zhongjinling south shaoguan smelter and severe pollution by zijin mining. The orderly degree of the price gradually decreases.

In 2012-2018, non-ferrous metal futures and stocks began to show steady fluctuations.

Compared with the non-ferrous metal futures subsystem, the non-ferrous metal stock subsystem has a higher degree of image coincidence, better consistency but greater overall fluctuation.

\subsection{Compare the synergy degree of different non-ferrous metals}

As can be seen from figure 3 , the collaborative evolution trend of copper and zinc futures price and stock price is similar, while the synergy degree of aluminum futures price and aluminum stock price is basically negative after 2008.Here, we use the latest daily data to support the views of huang hong and jiang xiaoquan (2010) that "the price discovery function of aluminum futures is inferior to that of copper and zinc futures".

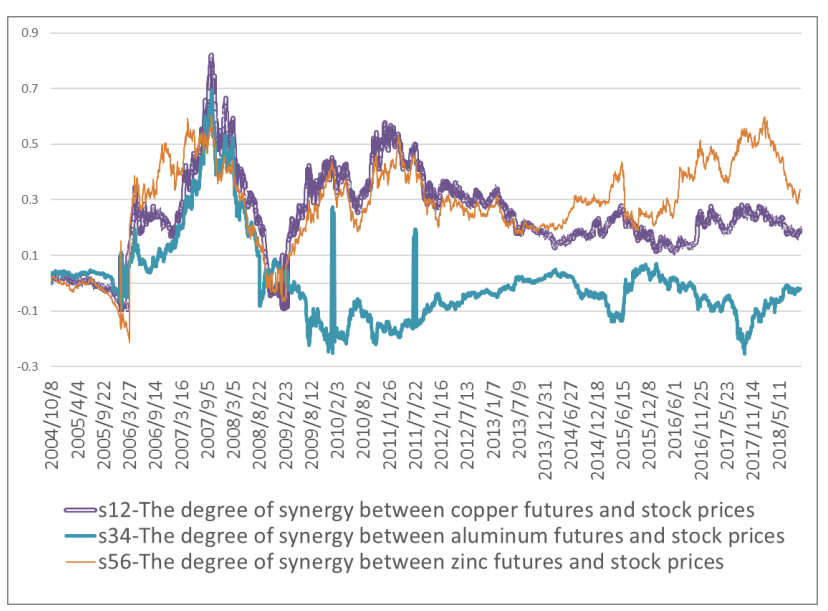

Figure 3. The joint comparison of price synergies of three nonferrous metal futures.

The main reasons for the low degree of synergy may be as follows: firstly, China's copper and zinc industries have low entry costs, diversified distribution of enterprises and sufficient competition, while the aluminum industry of China has some industry giants such as aluminum industry of China, which makes the whole industry lack competition. Secondly, enterprises in the copper and zinc industry have more extensive participation in the futures market than those in the aluminum industry. The copper and zinc related industries have taken advantage of the futures market for pricing and hedging, while many aluminum related enterprises with higher output have not taken advantage of the futures market for hedging.

\subsection{Compare the overall synergy between non- ferrous metal futures market and stock market}

It can be seen from figure 4 that the non-ferrous metal stock market has a good degree of synergy. Although there was a sharp shock during the economic crisis in 2007-2008, it finally began to show an upward trend at the end of 2008, and it was basically stable between 0.2 0.4 . 


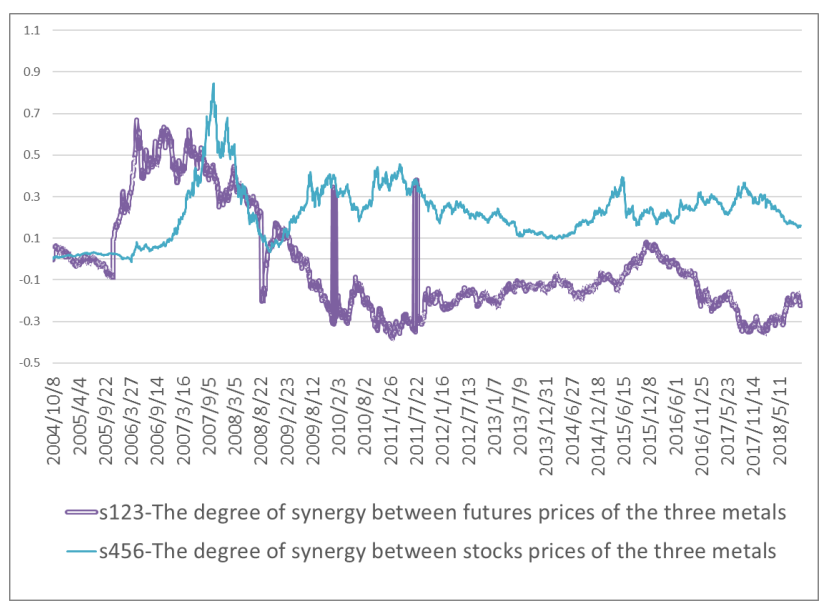

Figure 4. Non-ferrous metal futures market and the overall synergy of the stock market.

In the 3405 trading days, the minimum value of the non-ferrous metal stock market synergy indicator was 0.0147 , the maximum value was 0.8430 , and the average value was 0.2215. Over 3,398 trading days (about $99.79 \%$ ), the synergy indicator was greater than zero, with the most rapid declines concentrated in November 2007 and the smallest in October 2004, the beginning of the financialization of commodities.

And although the futures market was more synergistic than the stock market at the beginning of the enhanced financialization of commodities, it continued to decline after the 2007-2008 economic crisis and failed to recover.

In the 3405 trading days, the minimum value of the non-ferrous metal futures market synergy indicator was 0.3828 , the maximum value was 0.6698 , and the mean value was -0.0301 . The synergy indicator was less than 0 in 2,238 trading days (about 65.73\%), indicating that the futures market was generally uncoordinated for most of the time.The sharpest drop was in September 2008. The minimum was concentrated in February 2011.The synergy index as low as -0.2 indicates that the market is already in a seriously unstable state at this time, and the price movements of most commodities are independent.

\subsection{Discussion on the existence of industry representative metal}

According to the experimental results in fig.5 and fig.6, in terms of futures, cu-zinc futures showed good cooperative performance, while cu-aluminum and aluminum-zinc futures showed poor cooperative performance. In terms of stocks, most of the synergies between the three metals and other metals are between $0.2-0.5$. Although the performance is good, the images are highly overlapping and the differences are small.

To sum up, no metals representing the non-ferrous metal industry were found in this paper. This does not mean that this particular metal does not exist, because in the commodity market, the judgment of price advance cannot be totally dependent on the calculation of synergies, which can only measure the degree of coordination and cooperation among various elements in a system. Therefore, we can not deny the previous research results on industry representative metal.

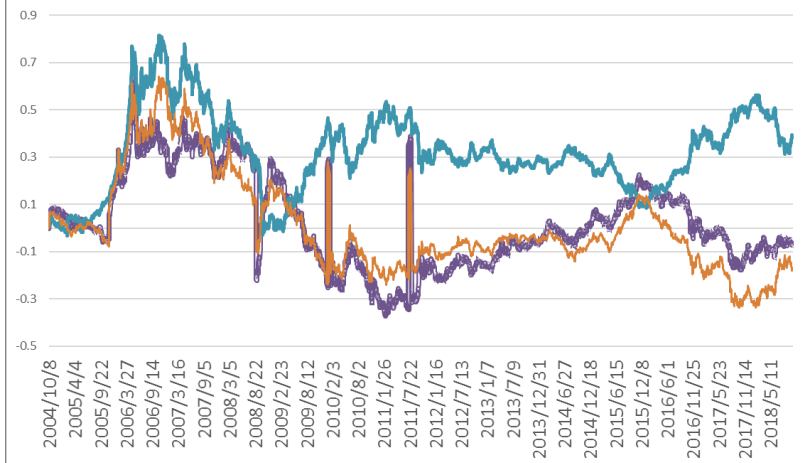

—s13-The degree of synergy between copper and aluminum futures prices - s15-The degree of synergy between copper and zinc futures prices - $s 35$-The degree of synergy between aluminum and zinc futures prices

Figure 5. The pairwise synergy of the non-ferrous metal (copper, aluminum, zinc) futures market.

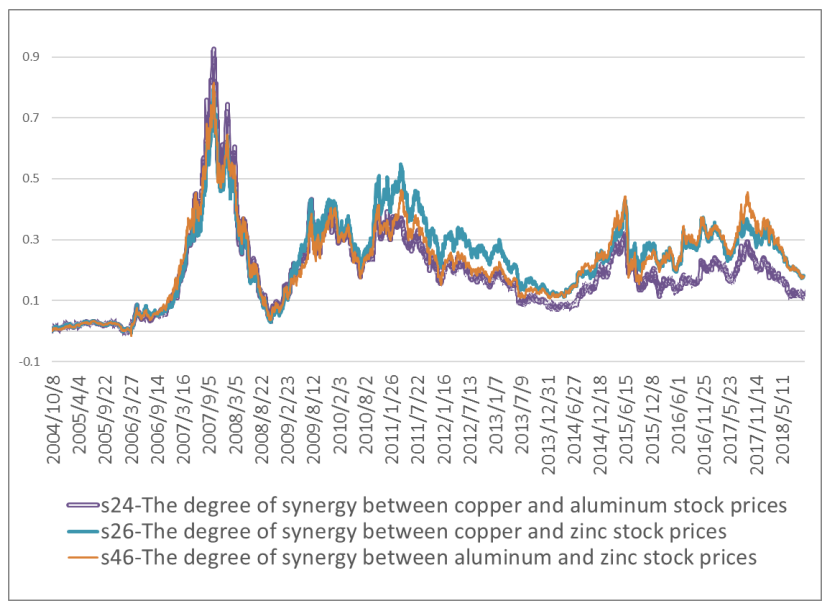

Figure 6. The pairwise synergy of the non-ferrous metal (copper, aluminum, zinc) stock market.

\section{Brief summary}

First, in a healthy and orderly market, multiple internal indicators should be able to explain and estimate each other. When the index changes abnormally, it reflects the degree of disorder of the market to some extent. When the maximum or minimum value of the synergy indicator appears, the potential risks and opportunities of the market should be noted. This is also the basic starting point of our collaborative analysis.

In addition, a high degree of synergy usually means a high degree of market stability. When there is less synergy in some markets, it is certain that markets are not very stable, even without the recent sharp price swings.

Finally, synergy indicators are not omnipotent and cannot replace correlation or other indicators. It has certain limitations, and can consider multiple market indicators or economic phenomena for joint analysis.

\section{References}

1. H. Bessembinder, Rev. Financ. Stud. 5(4):637-667 (2004)

2. G. Gorton, K.G. Rouwenhorst, Financ. Anal. J. 62(2):47-68. (2006) 
3. B. Büyükşahin, M.A. Robe, J. Int. Money. Financ. 42(2):38-70.(2013)

4. A.S. Kyle, W. Xiong, J. Financ. 56(4):1401-1440. (2001)
5. Y.N. Jia, D.P. Wang, Stud. Inter. Fin. (2). 2018

6. T. Ren, Z.B. Zhou, Chin. J. Manage. Sci. 25(8):7988. (2017) 